\title{
EDITORIAL V17 N1 (2022)
}

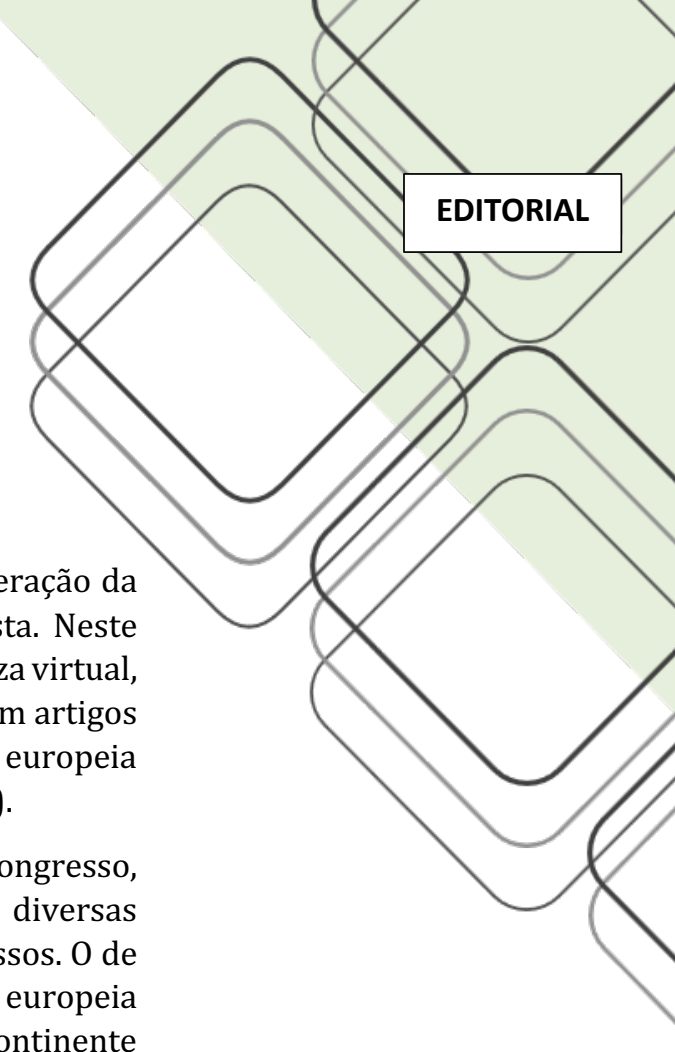
americano, por uma articulação muito bem-sucedida dos chairmen dos dois lados do Atlântico, Gonçalo Henriques, da UFRJ, no Brasil, e José Pedro Sousa e João Pedro Xavier, da FAUP, em Portugal, ampliando as oportunidades de intercâmbio.

O Congresso de 2020, intensamente atingido pela grave crise sanitária mundial decorrente da COVID-19, foi o primeiro da Sociedade a se realizar de forma totalmente remota, graças ao esforço incansável do Comitê Organizador Local presidido por Juliana Restrepo Jaramillo e David A. Torreblanca-Díaz, que levaram a cabo com reconhecido êxito a tarefa não apenas de planejar o congresso, mas de replanejá-lo - e executá-lo - em condições totalmente distintas das iniciais, em um período de incertezas constantes, dando-nos um senso de presença e lugar em Bogotá ainda que estivéssemos impedidos de viajar. Vale lembrar que o próprio desenvolvimento das pesquisas que originaram os artigos do congresso foi bastante afetado pelas condições de saúde e recomendações de isolamento impostas pela crise, com efeitos que perduram até hoje e apenas começam a ser mitigados - ao lado de imensas perdas humanas que serão sempre sentidas.

Ao trabalhar a partir de dois congressos, lidamos também com dois temas distintos e complementares. Em 2019, o tema "Architecture in the Age of the $4^{\text {th }}$ Industrial Revolution" procurou reunir trabalhos que lidassem com a transformação profunda nos modos de pensar e produzir o espaço. Em 2020, o tema "Transformative Design" traz a reflexão sobre o papel do projeto como meio de transformação do espaço e da sociedade, entendendo o papel do projetista como agente mediador - mas não isolado - dessa mudança. Após o congresso de 2020, procedemos aos convites a autores de trabalhos em destaque em ambos os congressos para que ampliassem, complementassem e se aprofundassem as contribuições de seus artigos originais.

Após o envio e novas rodadas de revisão, agora no âmbito da revista, chegamos aos quinze artigos aqui presentes. Em seu conjunto, descrevem um arco que vai do encontro da tecnologia com as demandas de projeto da sociedade até a elaboração simbólica da história mediada pelo computador, passando pelo projeto da cidade a partir de algoritmos e dados gerados em tempo real pelos seus habitantes. São trabalhos que trazem uma marca característica da própria SIGraDi, visto que se mostram preocupados mais do que com a simples e unívoca aplicação de determinada tecnologia em um dado campo; expressam como a própria técnica precisa se 
humanizar diante das situações apresentadas, abraçando as exceções, imperfeições e desvios que tornam as cidades organismos vivos e dinâmicos. Uma tecnologia entendida como parte de uma cultura e de um contexto social específico, sempre elaborada (programada, empregada ou ressignificada) por mãos humanas, que carregam seus próprios interesses e histórias.

0 artigo que abre a edição, "Tecnologias assistivas e deficiência: um encontro das mulheres-mães com a fabricação digital nos Fab Labs", de Juliana Maria Moreira Soares e Paulo Eduardo Fonseca de Campos, relata uma ação de criação e produção de objetos para auxiliar crianças com deficiência, realizada pelas mães dessas crianças. A descrição do processo traz uma visão dos Fab Labs como possíveis espaços de empoderamento e trocas de conhecimento plurais entre pessoas de diferentes experiências de vida, e ajuda a iluminar o potencial impacto desses novos equipamentos urbanos e da fabricação digital mesmo no cotidiano de uma população com pouca familiaridade com o pensamento digital.

"Making the logic: a methodological experience of digital design process for small urban interventions", de Megg Sousa, Denise Mônaco dos Santos, Andressa Martinez e Douglas Souza, o artigo seguinte, busca traduzir as relações socioespaciais e topológicas descritas na obra "Uma linguagem de padrões", de Christopher Alexander, Sara Ishikawa e Chris Silverstein, em algoritmos manipuláveis pelo computador. Para além de propor uma ferramenta de projeto, a operacionalização digital contribui para um melhor entendimento dos gestos projetuais envolvidos na produção do espaço urbano e arquitetônico.

No artigo seguinte, "O compartilhamento de saberes sobre o uso da modelagem paramétrica e da fabricação digital entre contextos formativos e profissionais de arquitetura: relato de caso", os autores Janice de Freitas Pires, Adriane Borda Almeida da Silva, Alexandre Berneira da Silva e Ramile da Silva Leandro procuram estudar o quanto desses gestos projetuais realizados por escritórios de arquitetura de Pelotas, no Rio Grande do Sul, envolvem modelagem paramétrica, ajudando a documentar um momento histórico de incorporação de um modo alternativo de pensar a arquitetura.

Como exemplo desse modo de pensar, temos "Exploring bio-parametric solution-based design process for an ephemeral pavilion", em que a investigação biomimética realizada pelos autores Elton Cristovão da Silva Lima, Cristina Matsunaga e Leticia Teixeira Mendes sobre o comportamento estrutural dos músculos humanos é fortemente influenciada pela construção de um algoritmo paramétrico de descrição das relações de força e forma envolvidas.

O exame dos sistemas estruturais do ponto de vista da descrição algorítmico-paramétrica é também objeto do artigo "Gridshells: integrating design with structural performance in early design stages, using formal and informal knowledge", de Gonçalo Castro Henriques e Juarez Moara Franco. Nele, os autores descrevem experimentos em form-finding, originados em workshops no Brasil e na Alemanha, envolvendo o design e produção digitais combinados com métodos analógicos, em que a imaginação arquitetônica é alimentada pelas diretrizes da engenharia e condicionada pela própria materialidade dos elementos construtivos.

As especulações didáticas são levadas adiante no artigo seguinte, "Variações formais em um sistema generativo: o sintagma como hipótese de controle semântico", de Pedro Engel. Nele, o autor lança mão da codificação algorítmica para construir um ambiente digital, denominado "Supergrid", para os alunos experimentarem com a composição de fachadas. 0 ambiente é baseado na estrutura de uma linguagem de padrões e na noção de "sintagma", traduzida no texto como um conjunto elementos formais organizados segundo regras arquitetônicas, trazendo para os alunos uma noção mais ampla das articulações e dependências entre esses elementos. 
O seminal trabalho de Christopher Alexander é também a base do artigo "Artefato metodológico do City Pattern: tradução computacional paramétrica de princípios de Christopher Alexander sobre forma e vida urbana", de Isabella Eloy Cavalcanti, Leticia Teixeira Mendes e Mauro N. M. Barros Filho. Tendo como objetivo a elaboração de processos de tradução de preceitos teóricos em algoritmos projetivos computáveis, os autores descrevem a base teórico-conceitual relacionada à programação do "City Pattern", com as etapas metodológicas correspondentes.

O problema da codificação formal dos assentamentos humanos é a base do artigo "Decoding and recoding informal settlements in a design studio: an overview of the World Studio Project", de Debora Verniz, Fernando T. Lima e José P. Duarte. Com base na gramática da forma e utilizando ferramentas paramétricas, os ateliês descritos no artigo, oferecidos anualmente na Pennsylvania State University desde 2017, buscam descrever alguns elementos fundamentais para projetos que envolvem assentamentos informais no Brasil e na Índia, fazendo com que o aprendizado das funções paramétricas se dê em função de situações urbanas sensíveis e de grande vulnerabilidade.

0 artigo "Assessing Brazilian peripheral sprawl: an association of computer-aided tools to evaluate spatial changes at Vila Cabral neighborhood, Campina Grande", de Frederico Costa, Jaqueline Brandão e Geovany Silva joga luz sobre o crescimento urbano, trazendo o foco para a leitura dos ambientes urbanos. Por meio de instrumentos computacionais como a sintaxe espacial e indicadores de densidade e uso, empregados para análise temporal em um bairro de Campinha Grande, na Paraíba, os autores contribuem para o desenvolvimento de métodos que ajudem a revelar novos padrões desse fenômeno.

Com o artigo "Proposição para um modelo de implementação computacional: Indicadores para o Verde Urbano (IVU)", as autoras Thayssa Barbosa da Silva Neves e Lucila Chebel Labaki conduzem as ferramentas de análise urbana para a cobertura vegetal das cidades, conduzindo testes em contextos urbanos fabricados e em trechos de João Pessoa, na Paraíba. Desse modo, tratam de conduzir a discussão do conforto ambiental a partir da lógica paramétrica para a escala urbana, e fornecem subsídios quantitativos para discussões de planejamento sobre elementos fundamentais para a regulação do clima nas cidades.

No artigo "Dados de conexões Wi-Fi e campus universitário: estudos sobre dinâmica humana e privacidade", os autores Luís Henrique Pavan, Lucas Fernandes de Oliveira, Camila Poeta Mangrich, Renato Luiz Martins de Almeida, Fernanda de Oliveira Gomes, Jean Everson Martina e José Ripper Kós realizam, também na escala urbana, três ensaios analíticos a partir dos dados produzidos por cada um dos usuários da rede sem fio do campus da Universidade Federal de Santa Catarina. Nesse processo, demonstram tanto o potencial desses dados para a gestão e planejamento do espaço universitário quanto a delicadeza das questões éticas envolvidas em seu uso, e a necessidade de critérios e protocolos que resguardem a privacidade desses usuários.

Com "Invisible informality and the contribution of information modeling to data-based urban regulation", os autores Mariana Quezado Costa Lima, Clarissa Figueiredo Sampaio Freitas e Daniel Ribeiro Cardoso vêm contribuir para os esforços de representação da cidade informal, ajudando a confrontar a cidade da legislação com a cidade real a partir da leitura do espaço urbano pela computação por dados georreferenciados, tendo Fortaleza (CE), como caso analisado. A partir da comparação da situação real dos lotes com os dados fundiários oficiais e com a morfologia urbana simulada a partir da legislação, foram identificados diversos descompassos nas áreas menos favorecidas da cidade, sinalizando a possível inadequação dos instrumentos oficiais tradicionais de registro e regulação em relação a essas áreas. 
O processamento computacional dos dados georreferenciados é igualmente a base para a construção metodológica do artigo "Mapa de confiabilidade: um método quantitativo para análise do grau de confiança nas reconstruções digitais de patrimônios históricos demolidos ou fortemente modificados", de Emerson Bruno de Oliveira Gomes, Talita Simão Luiz Araujo, Abner Simões Portilho Ferraz e Anna-Beatriz Bassalo Aflalo. Nele, os autores propõem que a interpolação desses dados dê origem a um mapa de cobertura fotográfica do centro urbano histórico de Belém, no Pará, aprimorando a base qualitativa de uso das fotografias antigas por meio da tradução numérica de alguns de seus atributos, contribuindo para a interpretação histórica e patrimonial do espaço estudado.

No artigo "Moderno digital: (re)construção da arquitetura moderna em Fortaleza", de Ricardo Alexandre Paiva, o redesenho em BIM é utilizado para a construção de um acervo de 52 edificações modernistas de Fortaleza, no Ceará. Nesse processo de interpretação históricoconstrutiva dos edifícios, a própria compreensão das obras é refinada, ajudando a compatibilizar as diferentes fontes. As diversas saídas propostas contribuem também para a constituição de uma base didática tanto para arquitetos em formação quanto de educação patrimonial em geral, além de potenciais usos na preservação dos edifícios.

O artigo que fecha a edição, “O Panorama do Rio de Janeiro de Victor Meirelles de Lima e Henri Charles Langerock: da interpretação histórica à experiência imersiva virtual em $\mathbf{3 6 0}^{\circ}$ ", de Thiago Leitão de Souza, dá continuidade ao uso das tecnologias digitais como auxiliar do processo de elaboração da história da cidade e dos seus meios de representação. Por meio de minuciosa reconstrução histórica e reinterpretação perspectiva, o trabalho busca se aproximar da experiência imersiva original de uma das pinturas panorâmicas do Rio de Janeiro, restituindo no processo a própria importância da pintura e do edifício que a abrigava para a cidade.

Com esta seleção de trabalhos, desejamos às leitoras e aos leitores deste número da Revista Gestão \& Tecnologia de Projetos que obtenham tantas respostas quanto novas e essenciais perguntas; que estes artigos ajudem a suas ideias e fomentar pesquisas futuras. Em nome do Comitê Executivo Internacional da SIGraDi, agradecemos aos autores que participaram com seus artigos, aos nossos revisores e ao corpo editorial da revista, na pessoa de seu editor-chefe, Dr. Marcio Minto Fabricio, por todo o auxílio no processo editorial e por dar-nos a oportunidade de realizar esta colaboração.

\section{Editores V17 | N1:}

Dr. Rodrigo Cury Paraizo, Programa de Pós-graduação em Urbanism, Faculdade de Arquitetura e Urbanismo, Universidade Federal do Rio de Janeiro, Brasil

Dra. Simone Helena Tanoue Vizioli, Instituto de Arquitetura e Urbanismo da Universidade de São Paulo, Brasil 